\title{
The yin and yang functions of extracellular ATP and adenosine in tumor immunity
}

\author{
Li-li Feng ${ }^{1} \mathbb{B}$, Yi-qing Cai ${ }^{1}$, Ming-chen Zhu ${ }^{5}$, Li-jie Xing ${ }^{1}$ and Xin Wang 1,2,3,4*
}

\begin{abstract}
Extracellular adenosine triphosphate (eATP) and its main metabolite adenosine (ADO) constitute an intrinsic part of immunological network in tumor immunity. The concentrations of eATP and ADO in tumor microenvironment (TME) are controlled by ectonucleotidases, such as CD39 and CD73, the major ecto-enzymes expressed on immune cells, endothelial cells and cancer cells. Once accumulated in TME, eATP boosts antitumor immune responses, while ADO attenuates immunity against tumors. EATP and ADO, like yin and yang, represent two opposite aspects from immuneactivating to immune-suppressive signals. Here we reviewed the functions of eATP and ADO in tumor immunity and attempt to block eATP hydrolysis, ADO formation and their contradictory effects in tumor models, allowing the induction of effective anti-tumor immune responses in TME. These attempts documented that therapeutic approaches targeting eATP/ADO metabolism and function may be effective methods in cancer therapy.
\end{abstract}

Keywords: Extracellular adenosine triphosphate, Adenosine, CD39, CD73, Tumor immunity

\section{Background}

Adenosine triphosphate, also known as ATP, is actively released to the extracellular environment in response to tissue damage and cellular stress. The concentration of cellular ATP is 3 to $10 \mathrm{mM}$. However, the concentration of extracellular ATP (eATP) is only about $10 \mathrm{nM}$ [1]. The concentration gradient is maintained by ecto-nucleotidases, such as CD39 and CD73, which hydrolyze released ATP rapidly to adenosine diphosphate (ADP), adenosine monophosphate (AMP), and then adenosine (ADO) [2]. CD39/ecto-nucleoside triphosphate diphosphohydrolase-1 (ENTPDase1) is the dominant ecto-nucleotidase broadly expressed on immune cells, endothelial cells (ECs) and tumor cells, which drives the sequential hydrolysis of ATP and ADP to AMP [3]. The formation of AMP to ADO is accomplished primarily through ecto-5-nucleotidase (CD73), a glycosyl phosphatidylinositol-linked

\footnotetext{
*Correspondence: xinw007@126.com

${ }^{1}$ Department of Hematology, Shandong Provincial Hospital Affiliated to Shandong University, Shandong First Medical University, Jinan 250021, Shandong, China

Full list of author information is available at the end of the article
}

membrane protein, also expressed on various immune cells, ECs and tumor cells [4].

Hypoxia, acute and chronic inflammation, platelet aggregation and anticancer therapies induce tumor cells death and metabolic changes, leading to the increased concentrations of eATP and ADO in tumor microenvironment (TME) [5]. The accumulation of extracellular nucleotides and nucleosides is negligible in healthy tissues, except in highly secluded compartments, such as synaptic clefts and the interstitium of exercising muscle $[6,7]$. However, the increase of eATP and ADO comprises important components in TME, which is a complex system consisting of host derived microvasculature, stroma, endothelial cells, pericytes, fibroblasts, smooth muscle cells and immune cells, characterized further by hypoxia, acidosis and high interstitial fluid pressure [8]. The components in TME communicate with each other, and also with cancer cells, regulating cellular processes which can inhibit or promote tumor growth [9]. They participate in tumor genesis and development through various mechanisms. In TME, eATP boosts antitumor immune responses while ADO attenuates immune response against tumors $[10,11]$. eATP and ADO, like

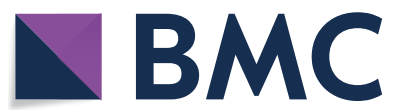

(c) The Author(s) 2020. This article is licensed under a Creative Commons Attribution 4.0 International License, which permits use, sharing, adaptation, distribution and reproduction in any medium or format, as long as you give appropriate credit to the original author(s) and the source, provide a link to the Creative Commons licence, and indicate if changes were made. The images or other third party material in this article are included in the article's Creative Commons licence, unless indicated otherwise in a credit line to the material. If material is not included in the article's Creative Commons licence and your intended use is not permitted by statutory regulation or exceeds the permitted use, you will need to obtain permission directly from the copyright holder. To view a copy of this licence, visit http://creativeco mmons.org/licenses/by/4.0/. The Creative Commons Public Domain Dedication waiver (http://creativecommons.org/publicdomain/ zero/1.0/) applies to the data made available in this article, unless otherwise stated in a credit line to the data. 
yin and yang, represent two opposite aspects from immune-activating to immune-suppressive signals in tumor immunity.

CD39, CD73, ATP and ADO have been proposed as therapeutic targets in oncology. Therapeutic strategies have been developed to modulate eATP/ADO metabolism and related anti-cancer immune responses. In this review, we focused on the effects and related mechanisms of eATP and ADO in tumor immunity, and then discussed the possibility of targeting purnergic signaling in cancer therapy.

\section{eATP and ATP receptors in TME}

Increased eATP in TME exhibits multiple functions in combination with ATP receptors. There are two P2 receptor families: P2X receptors (P2XR, P2X1-7) which are ATP-gated ion channels and $\mathrm{P} 2 \mathrm{Y}$ receptors which are G protein-coupled receptors (P2YR, P2Y1, 2, 4, 6, 11-14) [12]. Different P2 receptors have different affinity/specificity according to expressed cells, whereby modulating different cellular functions [13].

P2X1, 4, 5 receptors were found to express on multiple tumor cells and host cells, especially in hematological malignancies, including acute lymphocytic leukemia, acute myeloid leukemia and multiple myeloma $[14,15]$. Their activation mainly associated with the intracellular $\mathrm{Ca}^{2+}$ and $\mathrm{Na}^{+}$increase. In hematology malignancies and solid tumors, the activation of P2X7R not only increased intracellular $\mathrm{Ca}^{2+}$ and $\mathrm{Na}^{+}$but also decreased intracellular $\mathrm{K}^{+}$[14]. The roles of ATP were depending upon the concentration of eATP in TME. Low eATP levels were anticipated to promote cancer proliferation and immunosuppression, while high levels would promote antitumour immunity [14].

Different P2YR subtypes are activated by different nucleotides. ATP is the preferred ligand only for P2Y11R. For other P2YRs, pyrimidine nucleotides and ADP are more potent agonists. The expression of P2Y11R was found on Huh7 and HepG2 hepatocellular carcinoma cells, hematopoietic stem cells (HSCs) and dendritic cells (DCs) [14]. P2YRs are G protein-coupled and usually activate phospholipase C-IP3 pathway which modulates endoplasmic reticulum $\mathrm{Ca}^{2+}$ release. Three Gi/o-coupled subtypes (P2Y12, P2Y13 and P2Y14) mainly inhibit adenylyl cyclase to regulate cyclic AMP (cAMP)/protein kinase A (PKA) pathway [16, 17].

\section{eATP in tumor immunity}

Contemporary perspectives highlight the roles of TME in tumor growth and therapy. Increasing evidence indicated that targeting TME could complement traditional treatment and improve therapeutic outcomes for malignancies. As a major component, eATP in TME is at a high concentration $[18,19]$. The activation of P2X7R mediates high concentrated ATP-induced tumor cells death directly [20]. Besides the direct inhibition of tumor growth, eATP communicates with other immune cells in TME to regulate tumor growth (Fig. 1).

\section{eATP and monocytes (Mo)/macrophages (Mø)}

Tumor-associated macrophages (TAMs) are key members in TME. Macrophages (Mø) play different roles in tumor growth depending on their polarization to classically-activated macrophages (M1s, release tumor necrosis factor-alpha (TNF- $\alpha)$ ) or alternatively-activated macrophages (M2s, release IL-10) [21]. M1s conduct the pro-inflammation and anti-tumor effects, while M2s mainly exhibit anti-inflammation and tumor promoting effects. M2s play important roles in cancer cell survival, proliferation, stemness and invasiveness, along with angiogenesis and immunosuppression [22]. M1 cells have a low expression of ecto-nucleotidases and rate of ATP hydrolysis as compared to M2 cells [23]. The effects of eATP on Mo/Mø also depend on the levels of eATP and receptor subtypes. eATP at a high concentration functions as a danger signal activating P2X7R and leading to the activation of the NLRP3 proinflammatory inflammasome pathway in M1s [24]. Low levels of eATP and other nucleotides, such as ADP and UTP, activate the G-protein-coupled P2YRs to mediate chemotaxis of myeloid cells to damaged tissues [25]. eATP at micromolar concentration also fuctions as a chemoattractant for Mo migration to tumor [26]. In addition, eATP has a considerable impact on cytokine production from Mo/ Mø. eATP at millimolar concentration stimulates production of IL-1 $\alpha$, IL-1 $\beta$, IL-6, IL-18, chemokine (C-C motif) ligand (CCL)-2 and TNF- $\alpha$ [27] via P2X7 receptor expressed on Mo/Mø $[28,29]$. Recently, accumulated evidences supported the roles of multiple P2XR and P2YR subtypes in Mo/Mø, including P2X1R, P2X4R, P2X5R, P2X7R, P2Y2R, P2Y4R, P2Y6R, P2Y11R, P2Y13R and P2Y14R, which potentially conduct cytokine release and phagocytosis respectively [30]. Macrophage differentiation in the presence of ADO results in an M2-like phenotype [24]. The effects of extracellular nucleotides on M2 cells are mainly mediated by ADO (described below).

\section{eATP and DCs}

DCs are the most important antigen presenting cells (APCs) playing a pivotal role in tumor immunity. eATP not only affects DCs maturation and migration, but also contributes to the antigen endocytosis, cytokine production and ectonucleotidase expression. eATP induces up-regulation of activation and maturation markers (i.e. CD80, CD83, CD86, CD54, human leukocyte antigen DR (HLA-DR) and major histocompatibility complex 


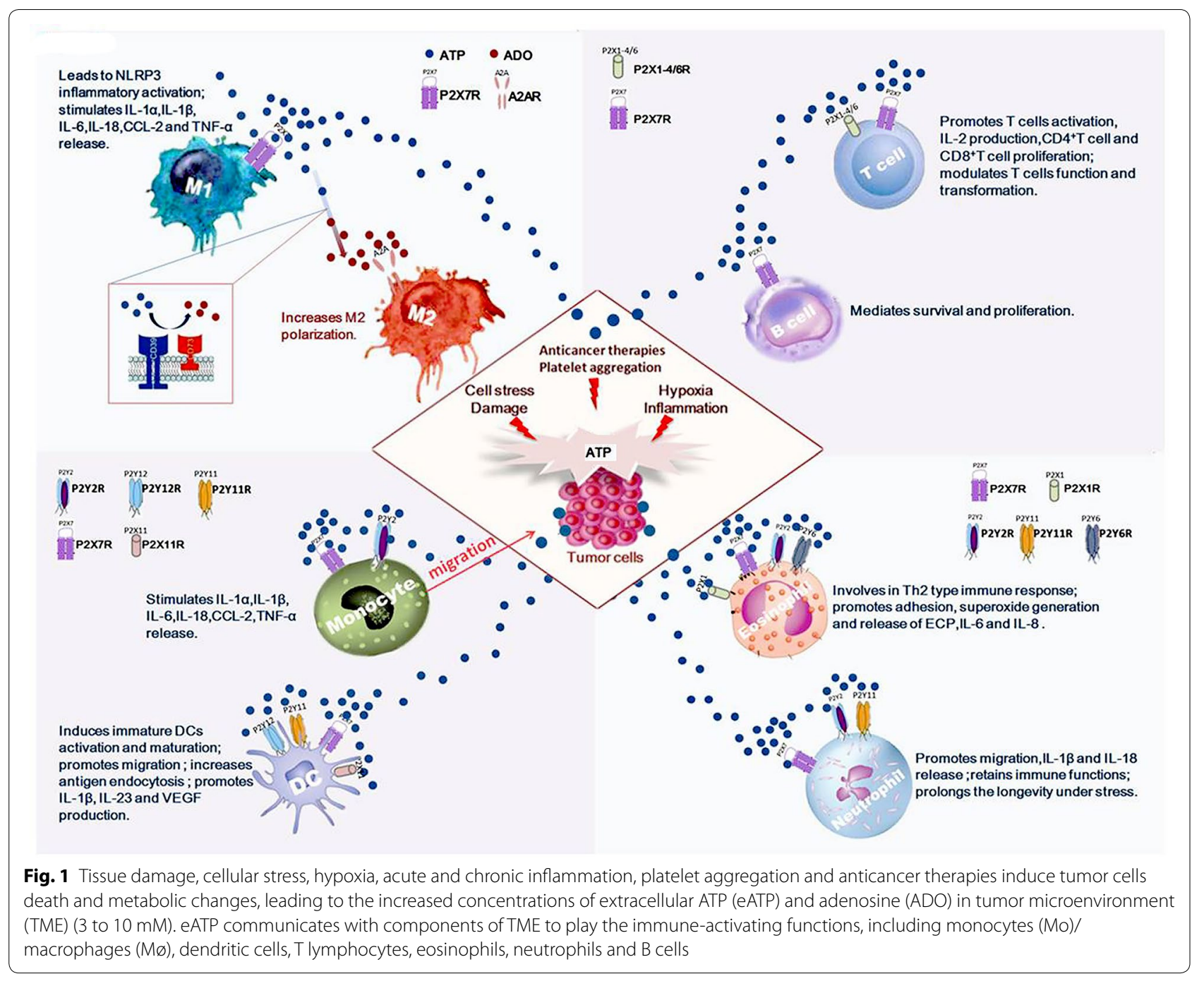

(MHC)-II) in human peripheral blood mononuclear cell (PBMC)-derived immature DCs, possibly by stimulation of P2Y11R and P2X7R [31]. Maturating DCs then migrate from peripheral tissues to $\mathrm{T}$ cells areas to deliver antigens and immunomodulatory messages [32]. Activation of P2Y12R increases antigen endocytosis of DCs with subsequent $\mathrm{T}$ cells activation [33]. eATP also has effects on cytokine production from DCs. It has been reported that eATP triggers NOD-like receptor family NLRP3-dependent caspase-1 activation complex ("inflammasome"), allowing the secretion of IL- $1 \beta$ through activation of P2X7R on DCs [34]. eATP is also found to promote IL-23 and vascular endothelial growth factor (VEGF) production from DCs in vitro, which is potentially mediated by P2Y11R [31, 35]. Higher IL-23 is essential for Th17 polarization and magnifying Th17-promoting activity of DCs [31]. However, when there is low level of eATP (uM), TNF- $\alpha$, IL-12 and IL-1 from DCs are completely abrogated [36]. It was recently reported that P2X7R was able to influence the expression of CD39 and CD73 on DCs. P2X7 pharmacological blockade leads to a reduction of tumor volume and an increase of extracellular ATP with conventional DCs down-modulate CD39 and CD73 [37]. In acute myeloid leukemia patients and mice, it was found that ATP release from chemotherapytreated dying cells increased number of $\mathrm{IDO}^{+} \mathrm{CD} 39^{+}$ DCs [38].

\section{eATP and T cells}

Recent studies have shown that eATP regulates $\mathrm{T}$ cell activation, cytokine production and lymphocyte metabolism [39, 40]. P2X receptor subtypes are found to involve in T-cell activation which requires a sustained elevation of intracellular $\mathrm{Ca}^{2+}$ levels. All P2XRs, with the exception of P2X5, can facilitate entry of $\mathrm{Ca}^{2+}$ in response to stimulation by eATP, suggesting that $\mathrm{P} 2 \mathrm{X}$ receptors regulate 
T-cell activation by increasing intracellular $\mathrm{Ca}^{2+}[41]$. P2XRs activation by ATP also protracts the T cell receptor (TCR)-initiated activity of MAPKs and secretion of IL-2 [42]. In contrary, removal of eATP or inhibition, mutation or silencing of $\mathrm{P} 2 \mathrm{X} 1, \mathrm{P} 2 \mathrm{X} 4$ or $\mathrm{P} 2 \mathrm{X} 7$ receptors inhibits $\mathrm{Ca}^{2+}$ entry, nuclear factors of activated $\mathrm{T}$ cells (NFAT) activation and T-cell activation [41, 43-45]. For T cells, P2X7R is found to distribute uniformly across the cell surface and can be activated by high concentration of eATP, occurring in damaged tissue and under cellular stress. This feature of P2X7R facilitates T cells to distinguish damaged tissues, especially in TME [46]. P2X7R also plays important roles in eATP $(100-300 \mu \mathrm{M})$ stimulated mitogen-induced $\mathrm{CD} 4^{+}$and $\mathrm{CD} 8^{+} \mathrm{T}$ cells proliferation. eATP also acts as a potent chemoattractant for T cells through P2YRs signaling [36]. Extracellular ATP produced by damaged tissue or exported by activated cells, is found not only triggers immune activation but plays an additional critical role by promoting metabolic fitness and survival of the most durable and functionally relevant memory $\mathrm{CD}^{+} \mathrm{T}$ cell populations through the activation of P2X7R [40].

Extracellular ATP and its receptor P2X7 also exert a pivotal influence on cancer growth through modulating lymphocytes infiltration in TME, including $\mathrm{CD} 4^{+}$, $\mathrm{CD}^{+}$lymphocytes and regulatory $\mathrm{T}$ cells (Tregs). Elena De Marchi et al. [37] reported that tumors growing in P2X7 null mice showed a decrease in $\mathrm{CD}^{+}$cells and an increased number of Tregs, overexpressing the fitness markers OX40, PD-1, and CD73. However, systemic administration of the P2X7 blocker A740003 in wild-type mice showed increased $\mathrm{CD} 4^{+}$effector cells and decreased their expression of CD39 and CD73. These data illustrated that $\mathrm{P} 2 \mathrm{X} 7$ receptor was a key determinant of TME composition.

In addition, eATP is a modulator for $\mathrm{T}$ cells function transformation. Antagonists of P2XRs can promote the cell-autonomous conversion of naive $\mathrm{CD} 4^{+} \mathrm{T}$ cells to Tregs after TCR stimulation [41]. The activation of P2X7R not only reduces Treg cells numbers, but also inhibits Treg cells generation, suppressive function and stability [38]. eATP released by commensal bacteria was also found to drive the differentiation of intestinal $\mathrm{CD} 4^{+}$ $\mathrm{T}$ cells to Th17 cells [1]. Another study confirmed that the activation of P2X7R on follicular helper $\mathrm{T}$ (Tfh) cells weakened germinal center reactions and immune globulin (Ig) A secretion, and resulted in increased serum IgM [46].

\section{eATP and eosinophils, neutrophils and B cells}

The participation of eosinophils in innate Th2-type immune responses is mediated by eATP [47]. eATP also promotes eosinophils functions through P2Y2R, including adhesion and superoxide generation [48]. Human eosinophils release eosinophil cationic protein (ECP), IL- 6 and IL- 8 by P2Y2 receptor stimulation, while P2X1, P2X7, and P2Y6 receptors might also be implicated in the release of IL-8 $[47,49]$. In hypoxia, neutrophils contribute to production of eATP. In return, the activation of P2Y2R by eATP promotes neutrophils migration to chemoattractants [50]. Neutrophils also express functional P2X7R, involving in the secretion of IL-1 $\beta$ and IL-18 [51]. In addition, activation of P2Y11R helps neutrophils to retain the immune functions and prolong the longevity under stress [30]. For B cells, the activation of P2X7R mainly mediates B-cell survival and proliferation [52].

\section{$A D O$ and $A D O$ receptors in TME}

Similar to eATP, the concentration of ADO is at a low level in extracellular media (lower than $1 \mu \mathrm{M}$ ). However, its concentration notably increases under many metabolically stressful conditions, especially in TME (over $100 \mu \mathrm{M})$ [19]. The bulk of extracellular ADO is generated from eATP thanks to sequential hydrolysis of CD39 and CD73 [17]. ADO binds to its receptors (A1, A2A, $\mathrm{A} 2 \mathrm{~B}$, and $\mathrm{A} 3$ ) presented on immune cells and tumor cells, regulating tumor progression and multiple immune responses, including tumor immunity [53]. A2A and A2B receptors (A2AR and $\mathrm{A} 2 \mathrm{BR}$ ) are Gs-coupled receptors that increase intracellular cAMP and PKA levels, playing dominant roles in ADO-induced immunosuppression in a cAMP-dependent manner [54]. A1 and A3 receptors (A1R and A3R) are Gi/o-coupled receptors that decrease intracellular cAMP, thereby favoring cell activation but also inducing activation of phosphatidylinositol 3-kinase (PI3K), extracellular-signal-regulated kinase (ERK)1/2 and protein kinase $C$ (PKC) $[55,56]$. Receptors with highaffinity (A1R, A2AR and A3R) are involved when ADO is at low concentrations, whereas at high concentrations, the low-affinity A2BR is involved, like those observed in TME [57].

ADO affects tumor progression directly through binding on its specific receptors expressed on cancer cells. Extracellular ADO in TME chronically activates A2BR expressed on cancer cells to suppress Ras-related protein (Rap)-1B prenylation and signaling, resulting in cell-cell contact reduction and cell scattering promotion. The major effect of A3R activation is to promote angiogenesis [58].

\section{Extracellular ADO in tumor immunity}

Extracellular ADO in TME is also an important factor controlling antitumor immunity, conditioning both innate and adaptive immune responses (Fig. 2). 


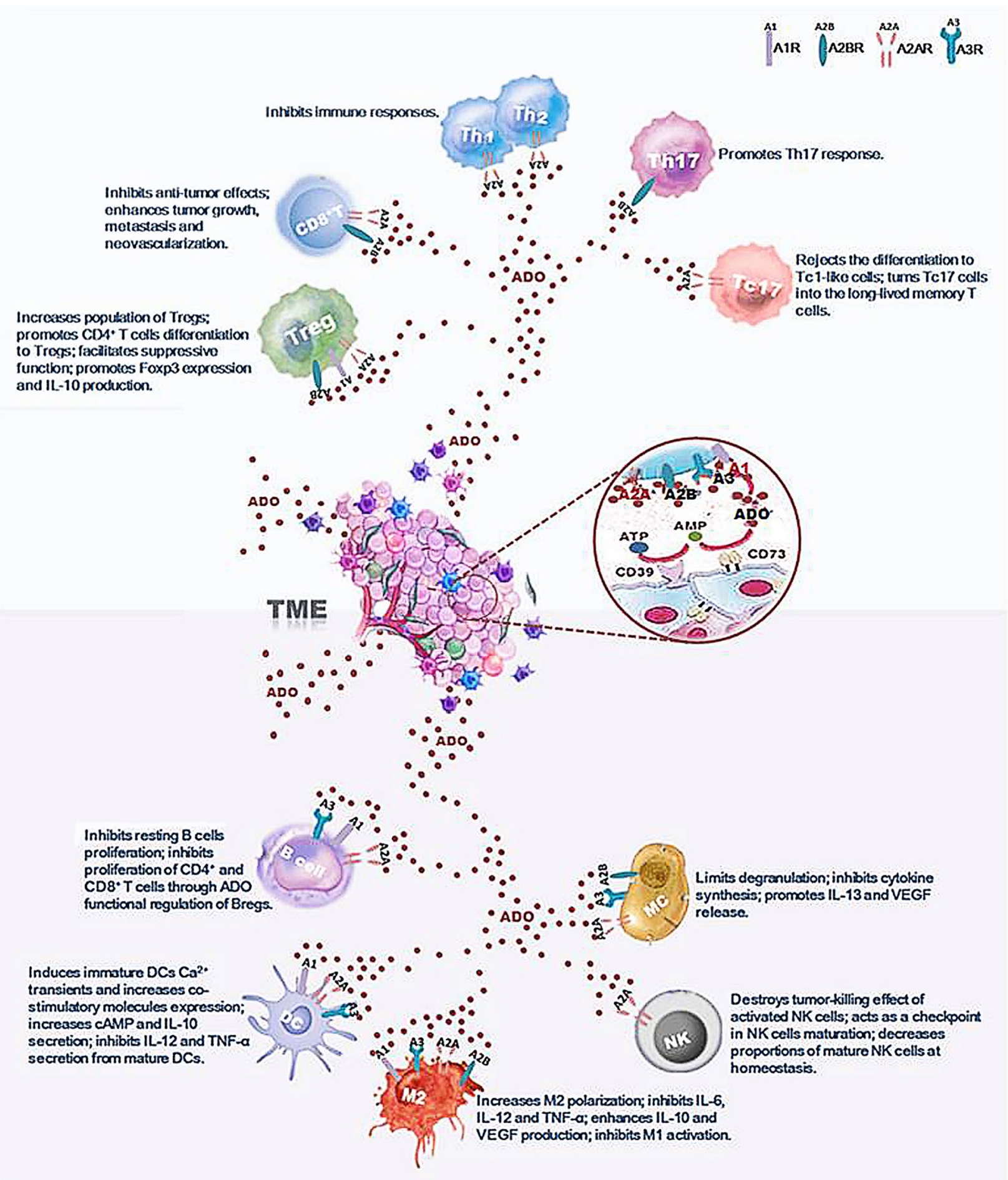

Fig. 2 Extracellular adenosine (ADO) at a high concentration (over $100 \mu \mathrm{M}$ ) conducted immune-suppressive functions through activation of different $A D O$ receptors on immune cells in tumor microenvironment (TME). For T cells in TME, ADO not only decreases anti-tumor function of CD8+T cells, Th1 cells and Th2 cells but also enhances the function of regulatory T cells (Treg), Th17 cells and Tc17 cells. ADO also affects B cells, dendritic cells (DCs), mast cells (MCs), natural killer (NK) cells and macrophages (Mø) functions in anti-tumor immunity 


\section{ADO and $T$ cells}

ADO is emerging as an important negative regulator of T-cell function for inhibition of mobility, migration and adhesion [59-61]. The inhibition role of ADO in antitumor $\mathrm{T}$ cells is mediated by A2AR and A2BR. Pharmacological blockade of A2AR not only enhances $\mathrm{CD}^{+} \mathrm{T}$ cells anti-tumor response but also reduces the population of Tregs [62]. A2AR antagonist or silence by siRNA could improve the inhibition of tumor growth, destruction of metastases and prevention of neovascularization by anti-tumor T cells [63]. For Treg cells, ADO not only promotes $\mathrm{CD} 4^{+} \mathrm{T}$ cells differentiation to Tregs [17], but also facilitates Treg cells suppressive function through A2AR activation [64]. Antagonists of A1R and A2BR also suppress the expression of Foxp3 and the production of IL-10 from Tregs [65]. Moreover, human Tregs overexpress CD39 and CD73, which are beneficial to ADO production. ADO then binds to A2AR on effector T cells and suppresses their functions [66]. Meanwhile, Treg cells express low levels of adenosine deaminase (ADA), the enzyme responsible for ADO breakdown, and CD26, a surface-bound glycoprotein associated to ADA, which is helpful to maintain the high concentration of ADO in TME [67]. A2AR activation on T cells under hypoxia could also suppress the development of Th1 and Th2 immune responses, both in vitro and in vivo [68]. A2BR is found to play important roles in the effects of ADO on Th17 cells. A2BR activation promotes Th17 response through DCs activation and differentiation from bone marrow cells to a $\mathrm{CD} 11 \mathrm{c}^{+} \mathrm{Gr}-1^{+} \mathrm{DC}$ subset $[69,70]$. Another subset of $\mathrm{T}$ cells, named Type 1 cytotoxic $\mathrm{CD} 8^{+}$ $\mathrm{T}$ (Tc1) cells, is latterly recognized as IL-17-producing CD8+ T (Tc17) cells. It is demonstrated that Tc17 cells stably sustain the stem-cell-like program and reject the differentiation to Tc1-like cells with the help of ADO, consequently activating A2AR, which turns Tc17 cells to long-lived memory $\mathrm{T}$ cells to allow the immunosuppressive properties in tumor progression [71].

\section{$A D O$ and $B$ cells}

Abundant expression of CD39 and CD73 on human B cells facilitates an efficient accumulation of ATP-generated $\mathrm{ADO}$, thus contributing to $\mathrm{T}$ cell-B cell interactions [72]. B cells have been found to express A1R, A2AR and A3R, but not A2BR. Agonists and antagonists studies were conducted to determine which ADO receptor was involved in B cells suppressive signals delivery. A selective A3R antagonist was found to stimulate proliferation of resting B-cells while a A3R agonist inhibited their proliferation, indicating that $\mathrm{ADO}$ produced by resting $\mathrm{B}$ cells exerted autocrine action [73]. Activated human B cells could also down-regulate proliferation of autologous
$\mathrm{CD}^{+}$and $\mathrm{CD}^{+} \mathrm{T}$ cells through ADO [73]. Recently, a new paradigm of regulatory $B$ cells (Bregs) was introduced [74] and they were thought to be able to control $\mathrm{CD}^{+}{ }^{+} \mathrm{T}$-cell responses [75]. Functional regulation of Bregs is manipulated by different $\mathrm{ADO}$ receptors respectively. A1R and A2AR contribute to the proliferation and functions of CD39 high $B$ cells while A2BR activation is critically required for IL-10 production [76].

\section{$A D O$ and $D C s$}

ADO, an important modulator of DCs functions, has significant effects on DCs activation, maturation, as well as cytokine production. A1R, A2AR and A3R are expressed by human monocyte-derived DCs. For immature DCs, ADO not only induces $\mathrm{Ca}^{2+}$ transients resulting in actin polymerization and chemotaxis, but also increases costimulatory molecules expression [30]. For mature DCs, ADO increases cAMP and IL-10 secretion while inhibits IL-12 and TNF- $\alpha$ production [77]. ADO is also found to activate human monocyte-derived DCs through A2AR [78] and murine bone marrow-derived dendritic cells (BMDCs) through A2BR [79]. However, unlike normal myeloid DCs, ADO-differentiated DCs have impaired allostimulatory activity and express high levels of angiogenic, pro-inflammatory, immune suppressor and tolerogenic factors [80]. ADO-conditioned DCs also have potential to regulate polarization of some T-cell subtypes. In vitro, $\mathrm{ADO}$-conditioned $\mathrm{DCs}$ reduce the capacity of Th1 polarization from $\mathrm{CD} 4^{+} \mathrm{T}$ cells in a cAMP-dependent manner [81]. DCs from A2BR agonist-treated mice showed a significantly increased ability to activate $\gamma \delta \mathrm{T}$ cells and Th17 autoreactive T cells [69]. Moreover, ADO deaminase knockout animal models showed that elevated levels of extracellular ADO were highly associated with DCs with a pro-angiogenic phenotype [82]. Therefore, a defective function of DCs under the activation of ADO-A2AR/A2BR axis in TME allows tumor to escape immune surveillance.

\section{ADO and mast cells (MCs)}

The amount of tumor-infiltrating MCs has a close relationship with tumor aggressiveness and dissemination [83]. A2AR, A2BR, and A3R are found to be expressed on MCs. A2BR activation limits cells degranulation [84]. The combination of $\mathrm{A} 2 \mathrm{AR}$ and $\mathrm{A} 2 \mathrm{BR}$ activation is required for the inhibition of cytokine synthesis both in vitro and in vivo $[85,86]$. MCs isolated from wild type (WT), not A2BR knocked out (KO) mice, release IL-13 and VEGF in response to extracellular ADO, suggesting the role of A2BR in angiogenesis [87]. However, A3R activation has been proven to mediate MCs activation through ERK1/2 phosphorylation in TME [88]. 


\section{$A D O$ and natural killer (NK) cells}

For NK cells, which are a type of innate immune cells, increased levels of adenosine in tumor environment inhibit the lytic activity of NK cells via binding to A2A receptors [89]. A2AR deletion increases proportions of mature NK cells at homeostasis, following reconstitution in TME. Targeting A2AR specifically on NK cells delays tumor genesis, suggesting A2AR-mediated signaling as an intrinsic negative regulator for NK cells maturation and antitumor immune responses [90].

\section{$A D O$ and $M \varnothing$}

Increased $\mathrm{ADO}$ concentration could also induce $\mathrm{Mø}$ recruitment in TME. Mø plays various roles in an ADOdependent manner [91]. A1R, A2AR, A2BR and A3R are all expressed on Mø cells. But the effects of ADO on Mø cells are predominantly mediated by A2AR. As described before, Mø cells played opposite roles depending on their polarization to M1s or M2s. A2AR activation leads to the increase of cAMP and the activation of CCAATenhancer-binding protein- $\beta$, thereby increase M2 macrophage polarization [92]. ADO also inhibits classical Mø activation [93]. For cytokine production, ADO not only inhibits TNF- $\alpha$, IL-6, and IL-12 release but also enhances IL-10 and VEGF production from Mø [94, 95].

\section{Targeting purinergic signaling as potential target in cancer therapy}

Given the yin and yang function of eATP and ADO in tumor immunity, targeting their signaling pathways and their metabolism has attracted more and more attention in tumor therapy.

\section{$P 2$ receptors as tumor therapeutic targets}

Among P2Rs, P2X7R is the most potential candidate in anticancer therapy [96]. P2X7R was reported to be expressed in multiple malignant tumors, including neuroblastoma [97], melanoma [98], prostate cancer [99], lung cancer [100] and breast cancer [101]. P2X7R antagonists could inhibit tumor growth and migration [96]. With pretreatment of P2X7R antagonists (including A-740003, A438079 and KN62), ATP-evoked tumor growth $(\mathrm{ATP}<1.0 \mathrm{mM})$ was inhibited via $\mathrm{PI} 3 \mathrm{~K} / \mathrm{AKT}$ and AMP-activated protein kinase (AMPK)/mTOR pathways [97, 102, 103]. Another P2X7R antagonist, named AZ10606120, was found to execute growthinhibitory effect in neuroblastoma through PI3K/ GSK3 $\beta /$ hypoxia-inducible factor 1-alpha (HIF-1 $\alpha$ ) pathway downregulation [104]. Moreover, P2X7R antagonists could affect inflammatory cytokines secretion. A740003 not only inhibited IL-10, IL-6 and monocyte chemoattractant protein-1 (MCP-1) release from macrophage [77], but also reduced cancer antigen presentation and cancer cell proliferation [105]. By downregulated CXCL1, MCP-1 and VEGF secretion, P2X7R antagonist (such as BBG and AZ10606120) contributed to inhibition of endothelial progenitor cells (EPCs) as well as vascular density and tumor neovascularization $[106,107]$. Another form of P2X7R, which is not able to form a functional pore and termed as non-pore functional P2X7R (nfP2X7R), has been described recently [101]. Researchers found that antibodies against amino acid sequence specifically for nfP2X7R also had a key role in cancer growth [108], which documented that antagonists specifically for nfP2X7R may be potential effective therapeutic agents in cancer therapy.

$\mathrm{P} 2 \mathrm{Y} 12 \mathrm{R}$ is another important member in P2R family. Under ATP and ADP stimulation, P2Y1R initiates platelet activation followed by the ADP-P2Y12R-mediated amplification [109]. P2Y12R represents a potential target in cancer therapy due to its involvement in platelet-cancer cell crosstalk. Thus, P2Y12R antagonists, including clopidogrel, ticagrelor and prasugrel, might represent potential anti-cancer agents [110].

\section{$A D O$ receptors as tumor therapeutic targets}

Strategies targeting ADO receptors appear to be attracting approaches to block ADO immunosuppressive effects and boost anti-tumor immunity. In a sarcoma model and the poorly immunogenic LL-LCMV tumor model, pharmacologic blockade of A2AR enhanced $T$ cell mediated tumor regression [63]. The ability of A2AR blockade to suppress metastatic has also been validated [111]. A2AR blockade and programmed death-1 (PD-1)/cytotoxic T-lymphocyteassociated antigen 4 (CTLA-4) monoclonal antibody $(\mathrm{mAb})$ combined therapy also illustrated impressive effects in a variety of syngeneic tumor models [112]. Most recently, it was reported that A2AR blockade had high potential to enhance chimeric antigen receptor (CAR)-T cells efficacy in some cancers [113]. There are some agents targeting the A2AR for cancer immunotherapy in Phase 1 trials, including CPI-444 (Corvus), PBF-509 (Novartis/Pablobiofarma), MK-3814 (Merck), AZD4635 (AstraZeneca/Heptares). Each of these trials includes cohorts receiving monotherapy as well as A2AR blockade in combination with blockade of the PD-1/PD-L1 pathway [114]. A2BR is a low-affinity receptor, but its expression is highly transcriptionally regulated by HIF- $1 \alpha$ in TME. When tumor A2BR was blocked, the decreased metastasis was observed in multiple tumors [80, 115]. A2BR inhibitor also showed significant anti-tumor effects when combined with anti-PD-1 and anti-CTLA-4 mAbs [115]. 


\section{CD39 and CD73 as tumor therapeutic targets}

Considering critical roles of CD39/CD73 in ATP/ADO metabolism, attempts to block CD39/CD73 activity have been tried in tumor therapy. When compared to CD39 over-expressing mice, colorectal cancer cells and melanoma cells in CD39 deficient models showed significantly slower hepatic and pulmonary metastases [116]. Inhibition of CD39 activity by polyoxometalate1 (POM-1) abrogated production of IL-10 from TAMs, functionally diminished immunosuppressive functions [117]. Even for sarcoma, which lacked effective therapeutic intervention, CD39 inhibitory mAb was proven to have prolonged survival in a lethal metastatic patient-derived sarcoma model [118]. Some pharmaceutical companies are currently developing anti-human CD39 mAb, such as Innate Pharma in France. CD73 blockade was also found to have favorable antitumor effects via modulating immune response in TME. CD73-deficient mice were demonstrated to sustain activated antitumor immunity, influencing neovascularization, tumor growth and metastasis [119, 120]. CD73 inactivation was proved to inhibit progression of breast cancer and head and neck squamous cell carcinoma [121, 122]. Likewise, anti-CD73 blocking antibody was also documented to impact spontaneous lung metastasis and decrease circulation capability of cancer cells [4]. Anti-CD39 and anti-CD73 monoclonal antibodies and their combination with immune checkpoint inhibitors and chemotherapies in cancer also showed promoted antitumor immunity [123]. CD73 inhibitors alone and in combination with other drugs in cancer patients are currently under clinical trials (such as NCT03454451, NCT02503774 and NCT03381274 registered at clinicaltrials.gov).

\section{Conclusions and future perspectives}

Purinergic signaling has emerged as a novel mechanism to modulate anticancer immunity. The accumulations of eATP and ADO in TME play yin and yang functions in tumor immunity through their specific receptors. The metabolism from eATP to ADO is accomplished mainly through CD39 and CD73, which expressed on immune cells, endothelial cells as well as cancer cells in TME. Drugs and biological approaches blocking eATP hydrolysis, ADO formation and their effects have the potential to overcome tumor immunosuppression, allowing the induction of effective anti-tumor immune responses. This strategy could also be a new option to improve the efficacy of cytotoxic agents and checkpoint blockade inhibitors. However, given the multifaceted effects of eATP and ADO in TME, where tumor cells, host immune cells and stromal cells communicate with each other through complicated mechanisms, how to select the most suitable therapy target is still a challenge to be overcome.

\begin{abstract}
Abbreviations
ADO: Adenosine; ADP: Adenosine diphosphate; AMP: Adenosine monophosphate; AMPK: AMP-activated protein kinase; APCs: Antigen presenting cells; ATP: Adenosine triphosphate; BMDCs: Bone marrow-derived dendritic cells; Bregs: Regulatory B cells; CAMP: Cyclic adenosine monophosphate; CAR: Chimeric antigen receptor; $\mathrm{CCL}$ : Chemokine (C-C motif) ligand; CTLA-4: Cytotoxic T-lymphocyte-associated antigen 4; DCs: Dendritic cells; eATP: Extracellular adenosine triphosphate; ECs: Endothelial cells; EPCs: Endothelial progenitor cells; ERK: Extracellular-signal-regulated kinase; HIF-1a: Hypoxia-inducible factor 1-alpha; HLA-DR: Human leukocyte antigen DR; HSC: Hematopoietic stem cells; Ig: Immune globulin; IL: Interleukin; KO: Knocked out; mAb: Monoclonal antibody; MCP-1: Monocyte chemoattractant protein-1; MCs: Mast cells; MHC: Major histocompatibility complex; Mo: Monocytes; Mø: Macrophages; NFAT: Nuclear factors of activated T cells; nfP2X7R: Non-pore functional P2X7R; NK: Natural killer; PBMC: Peripheral blood mononuclear cell; PD-1: Programmed death-1; PI3K: Phosphatidylinositol 3-kinase; PKA: Protein kinase A; PKC: Protein kinase C; POM-1: Polyoxometalate1; P2XR: P2X receptors; P2YR: P2Y receptors; Rap: Ras-related protein; TAMs: Tumor-associated macrophages; TCR: T cell receptor; Tfh: Follicular helper T cell; TME: Tumor microenvironment; TNF-a: Tumor necrosis factor-alpha; Tregs: Regulatory T cells; VEGF: Vascular endothelial growth factor; WT: Wild type.
\end{abstract}

Acknowledgements

Not applicable.

\section{Authors' contributions}

XW designed the review. LLF and YQC drafted the manuscript. MCZ and LJX helped modify the manuscript. All authors read and approved the final manuscript.

\section{Funding}

This study was supported by Grants from National Natural Science Foundation(No. 81500123, 81270598, 81473486 and No. 81770210); Key Research and Development Projects of Shandong Province (No. 2017G006005 and No. 2018CXGC1213), Technology Development Projects of Shandong Province (No. 2017GSF18189); Promotive Research Fund for Excellent Young and Middle-aged Scientists of Shandong Province (No. BS2013YY003), Natural Science Foundations of Shandong Province (No. ZR2016HP12); Taishan Scholar Program of Shandong Province; Shandong Provincial Engineering Research Center of Lymphoma; Key Laboratory for Kidney Regeneration of Shandong Province; Academic promotion programme of Shandong First Medical University.

Availability of data and materials

No datasets were generated or analysed

Ethics approval and consent to participate Not applicable.

\section{Consent of publication}

All authors have reviewed the manuscript and agree to publish it in its current form.

\section{Competing interests}

The authors declare that they have no competing interests.

\section{Author details}

${ }^{1}$ Department of Hematology, Shandong Provincial Hospital Affiliated to Shandong University, Shandong First Medical University, Jinan 250021, Shandong, China. ${ }^{2}$ School of Medicine, Shandong University, Jinan 250012, Shandong, China. ${ }^{3}$ Shandong Provincial Engineering Research Center of Lymphoma, Jinan 250021, Shandong, China. ${ }^{4}$ National clinical research center for hematologic diseases, Jinan 250021, Shandong, China. ${ }^{5}$ Department of Clinical 
Laboratory, Nanjing Medical University Cancer Hospital \& Jiangsu Cancer Hospital, Nanjing 210009, Jiangsu, China.

\section{Received: 20 June 2019 Accepted: 27 March 2020}

Published online: 07 April 2020

\section{References}

1. Trautmann A. Extracellular ATP in the immune system: more than just a "danger signal". Sci Signal. 2009;2(56):pe6.

2. Ferrari D, Gambari R, Idzko M, Muller T, Albanesi C, Pastore S, et al. Purinergic signaling in scarring. FASEB J. 2016;30(1):3-12.

3. de Andrade Mello P, Coutinho-Silva R, Savio LEB. Multifaceted effects of extracellular adenosine triphosphate and adenosine in the tumor-host interaction and therapeutic perspectives. Front Immunol. 2017:8:1526.

4. Antonioli L, Yegutkin GG, Pacher P, Blandizzi C, Hasko G. Anti-CD73 in cancer immunotherapy: awakening new opportunities. Trends Cancer. 2016;2(2):95-109.

5. Cai $Y$, Feng $L$, Wang $X$. Targeting the tumor promoting effects of adenosine in chronic lymphocytic leukemia. Crit Rev Oncol Hematol. 2018;126:24-31.

6. Burnstock G. Physiology and pathophysiology of purinergic neurotransmission. Physiol Rev. 2007:87(2):659-797.

7. Forrester T. A case of serendipity. Purinergic Signal. 2008;4(2):93-100.

8. Spaw M, Anant S, Thomas SM. Stromal contributions to the carcinogenic process. Mol Carcinog. 2017;56(4):1199-213.

9. Gilabert-Oriol R, Ryan GM, Leung AWY, Firmino NS, Bennewith KL, Bally MB. Liposomal formulations to modulate the tumour microenvironment and antitumour immune response. Int J Mol Sci. 2018;19(10):2922.

10. Regateiro FS, Cobbold SP, Waldmann H. CD73 and adenosine generation in the creation of regulatory microenvironments. Clin Exp Immunol. 2013;171(1):1-7. https://doi.org/10.1111/j.1365-2249.2012.04623.x

11. Li XY, Moesta AK, Xiao C, Nakamura K, Casey M, Zhang H, et al. Targeting CD39 in cancer reveals an extracellular ATP- and inflammasome-driven tumor immunity. Cancer Discov. 2019;9(12):1754-73.

12. Burnstock G, Di Virgilio F. Purinergic signalling and cancer. Purinergic Signal. 2013;9(4):491-540.

13. Di Virgilio F, Falzoni S, Giuliani AL, Adinolfi E. P2 receptors in cancer progression and metastatic spreading. Curr Opin Pharmacol. 2016;29:17-25

14. Di Virgilio F, Sarti AC, Falzoni S, De Marchi E, Adinolfi E. Extracellular ATP and $\mathrm{P} 2$ purinergic signalling in the tumour microenvironment. Nat Rev Cancer. 2018;18(10):601-18.

15. Adinolfi E, Capece M, Amoroso F, De Marchi E, Franceschini A. Emerging roles of P2X receptors in cancer. Curr Med Chem. 2015;22(7):878-90.

16. Abbracchio MP, Burnstock G, Verkhratsky A, Zimmermann H. Purinergic signalling in the nervous system: an overview. Trends Neurosci. 2009;32(1):19-29.

17. Stagg J, Smyth MJ. Extracellular adenosine triphosphate and adenosine in cancer. Oncogene. 2010;29(39):5346-58

18. Kepp O, Loos F, Liu P, Kroemer G. Extracellular nucleosides and nucleotides as immunomodulators. Immunol Rev. 2017;280(1):83-92.

19. Di Virgilio F, Adinolfi E. Extracellular purines, purinergic receptors and tumor growth. Oncogene. 2017;36(3):293-303.

20. Salvestrini V, Orecchioni S, Talarico G, Reggiani F, Mazzetti C, Bertolini F, et al. Extracellular ATP induces apoptosis through P2X7R activation in acute myeloid leukemia cells but not in normal hematopoietic stem cells. Oncotarget. 2017;8(4):5895-908.

21. Raiha MR, Puolakkainen PA. Tumor-associated macrophages (TAMs) as biomarkers for gastric cancer: a review. Chronic Dis Transl Med. 2018;4(3):156-63.

22. Najafi M, Hashemi Goradel N, Farhood B, Salehi E, Nashtaei MS, Khanlarkhani N, et al. Macrophage polarity in cancer: a review. J Cell Biochem. 2018;120(3):2756-65.

23. Zanin RF, Braganhol E, Bergamin LS, Campesato LF, Filho AZ, Moreira JC, et al. Differential macrophage activation alters the expression profile of NTPDase and ecto-5'-nucleotidase. PLoS ONE. 2012;7(2):e31205.
24. Barbera-Cremades M, Baroja-Mazo A, Pelegrin P. Purinergic signaling during macrophage differentiation results in M2 alternative activated macrophages. J Leukoc Biol. 2016;99(2):289-99.

25. Kronlage M, Song J, Sorokin L, Isfort K, Schwerdtle T, Leipziger J, et al. Autocrine purinergic receptor signaling is essential for macrophage chemotaxis. Sci Signal. 2010;3(132):ra55.

26. Chekeni FB, Ravichandran KS. The role of nucleotides in apoptotic cell clearance: implications for disease pathogenesis. J Mol Med. 2011:89(1):13-22.

27. He Y, Taylor N, Fourgeaud L, Bhattacharya A. The role of microglial P2X7: modulation of cell death and cytokine release. J Neuroinflamm. 2017;14(1):135.

28. Zanin RF, Bergamin LS, Morrone FB, Coutinho-Silva R, de Souza Wyse AT, Battastini AM. Pathological concentrations of homocysteine increases IL-1 beta production in macrophages in a P2X7, NF-kB, and erk-dependent manner. Purinergic Signal. 2015;11(4):463-70.

29. Barbera-Cremades M, Gomez Al, Baroja-Mazo A, Martinez-Alarcon L, Martinez CM, de Torre-Minguela C, et al. P2X7 receptor induces tumor necrosis factor-alpha converting enzyme activation and release to boost TNF-alpha production. Front Immunol. 2017;8:862.

30. Burnstock G, Boeynaems JM. Purinergic signalling and immune cells. Purinergic Signal. 2014;10(4):529-64.

31. Paustian C, Taylor P, Johnson T, Xu M, Ramirez N, Rosenthal KS, et al. Extracellular ATP and Toll-like receptor 2 agonists trigger in human monocytes an activation program that favors T helper 17. PLoS ONE. 2013;8(1):e54804.

32. Chen K, Wang JM, Yuan R, Yi X, Li L, Gong W, et al. Tissue-resident dendritic cells and diseases involving dendritic cell malfunction. Int Immunopharmacol. 2016;34:1-15.

33. Ben Addi A, Cammarata D, Conley PB, Boeynaems JM, Robaye B. Role of the $\mathrm{P} 2 \mathrm{Y} 12$ receptor in the modulation of murine dendritic cell function by ADP. J Immunol. 2010;185(10):5900-6.

34. Campesato LF, Silva APM, Cordeiro L, Correa BR, Navarro FCP, Zanin RF, et al. High IL-1R8 expression in breast tumors promotes tumor growth and contributes to impaired antitumor immunity. Oncotarget. 2017;8(30):49470-83.

35. Bles N, Horckmans M, Lefort A, Libert F, Macours P, El Housni H, et al. Gene expression profiling defines ATP as a key regulator of human dendritic cell functions. J Immunol. 2007;179(6):3550-8.

36. Jacob F, Perez Novo C, Bachert C, Van Crombruggen K. Purinergic signaling in inflammatory cells: $\mathrm{P} 2$ receptor expression, functional effects, and modulation of inflammatory responses. Purinergic Signal. 2013;9(3):285-306.

37. De Marchi E, Orioli E, Pegoraro A, Sangaletti S, Portararo P, Curti A, et al. The P2X7 receptor modulates immune cells infiltration, ectonucleotidases expression and extracellular ATP levels in the tumor microenvironment. Oncogene. 2019;38(19):3636-50.

38. Lecciso M, Ocadlikova D, Sangaletti S, Trabanelli S, De Marchi E, Orioli E, et al. ATP Release from chemotherapy-treated dying leukemia cells elicits an immune suppressive effect by increasing regulatory $T$ cells and tolerogenic dendritic cells. Front Immunol. 2017;8:1918.

39. Zhao R, Liang D, Sun D. Blockade of extracellular ATP effect by oxidized ATP effectively mitigated induced mouse experimental autoimmune uveitis (EAU). PLoS ONE. 2016;11(5):e0155953.

40. Borges da Silva H, Beura LK, Wang H, Hanse EA, Gore R, Scott MC, et al. The purinergic receptor P2RX7 directs metabolic fitness of longlived memory CD8(+) T cells. Nature. 2018;559(7713):264-8.

41. Woehrle T, Yip L, Elkhal A, Sumi Y, Chen Y, Yao Y, et al. Pannexin-1 hemichannel-mediated ATP release together with $P 2 X 1$ and $P 2 X 4$ receptors regulate $T$-cell activation at the immune synapse. Blood. 2010;116(18):3475-84.

42. Yu T, Junger WG, Yuan C, Jin A, Zhao Y, Zheng $X$, et al. Shockwaves increase T-cell proliferation and IL-2 expression through ATP release, P2X7 receptors, and FAK activation. Am J Physiol Cell Physiol. 2010;298(3):C457-64.

43. Adinolfi E, Callegari MG, Cirillo M, Pinton P, Giorgi C, Cavagna D, et al. Expression of the $\mathrm{P} 2 \mathrm{X} 7$ receptor increases the $\mathrm{C} 2 \mathrm{2}+$ content of the endoplasmic reticulum, activates NFATC1, and protects from apoptosis. J Biol Chem. 2009;284(15):10120-8. 
44. Yip L, Woehrle T, Corriden R, Hirsh M, Chen Y, Inoue Y, et al. Autocrine regulation of T-cell activation by ATP release and $\mathrm{P} 2 \mathrm{X} 7$ receptors. FASEB J. 2009;23(6):1685-93.

45. Kataoka A, Tozaki-Saitoh H, Koga Y, Tsuda M, Inoue K. Activation of P2X7 receptors induces CCL3 production in microglial cells through transcription factor NFAT. J Neurochem. 2009;108(1):115-25.

46. Salles EM, Menezes MN, Siqueira R, Borges da Silva H, Amaral EP, Castillo-Mendez SI, et al. P2X7 receptor drives Th1 cell differentiation and controls the follicular helper $T$ cell population to protect against Plasmodium chabaudi malaria. PLoS Pathogens. 2017;13(8):e1006595.

47. Kobayashi T, Kouzaki H, Kita H. Human eosinophils recognize endogenous danger signal crystalline uric acid and produce proinflammatory cytokines mediated by autocrine ATP. J Immunol. 2010;184(11):6350-8.

48. Kobayashi T, Soma T, Noguchi T, Nakagome K, Nakamoto H, Kita H, et al. ATP drives eosinophil effector responses through P2 purinergic receptors. Allergol Int. 2015;64(Suppl):S30-6.

49. Idzko M, Panther E, Bremer HC, Sorichter S, Luttmann W, Virchow CJ, et al. Stimulation of P2 purinergic receptors induces the release of eosinophil cationic protein and interleukin-8 from human eosinophils. Br J Pharmacol. 2003:138(7):1244-50.

50. Chen Y, Corriden R, Inoue Y, Yip L, Hashiguchi N, Zinkernagel A, et al. ATP release guides neutrophil chemotaxis via $\mathrm{P} 2 \mathrm{Y} 2$ and $\mathrm{A} 3$ receptors. Science. 2006;314(5806):1792-5.

51. Karmakar M, Katsnelson MA, Dubyak GR, Pearlman E. Neutrophil P2X7 receptors mediate NLRP3 inflammasome-dependent IL-1 beta secretion in response to ATP. Nat Commun. 2016;7:10555.

52. Adinolfi E, Melchiorri L, Falzoni S, Chiozzi P, Morelli A, Tieghi A, et al. P2X7 receptor expression in evolutive and indolent forms of chronic $B$ lymphocytic leukemia. Blood. 2002;99(2):706-8.

53. Jin D, Fan J, Wang L, Thompson LF, Liu A, Daniel BJ, et al. CD73 on tumor cells impairs antitumor T-cell responses: a novel mechanism of tumorinduced immune suppression. Cancer Res. 2010;70(6):2245-55.

54. Sorrentino R, Pinto A, Morello S. The adenosinergic system in cancer: key therapeutic target. Oncoimmunology. 2013;2(1):e22448.

55. Taylor SS, llouz R, Zhang P, Kornev AP. Assembly of allosteric macromolecular switches: lessons from PKA. Nat Rev Mol Cell Biol. 2012;13(10):646-58.

56. Tsuchiya A, Nishizaki T. Anticancer effect of adenosine on gastric cancer via diverse signaling pathways. World J Gastroenterol. 2015;21(39):10931-5.

57. Kazemi MH, Raoofi Mohseni S, Hojjat-Farsangi M, Anvari E, Ghalamfarsa $\mathrm{G}$, Mohammadi $\mathrm{H}$, et al. Adenosine and adenosine receptors in the immunopathogenesis and treatment of cancer. J Cell Physiol. 2018;233(3):2032-57.

58. Ghiringhelli F, Bruchard M, Chalmin F, Rebe C. Production of adenosine by ectonucleotidases: a key factor in tumor immunoescape. J Biomed Biotechnol. 2012;2012:473712.

59. Chimote AA, Hajdu P, Kucher V, Boiko N, Kuras Z, Szilagyi O, et al. Selective inhibition of $\mathrm{KCa} 3.1$ channels mediates adenosine regulation of the motility of human T cells. J Immunol. 2013;191 (12):6273-80

60. Ring S, Oliver SJ, Cronstein BN, Enk AH, Mahnke K. CD4+ CD25+ regulatory $T$ cells suppress contact hypersensitivity reactions through a CD39, adenosine-dependent mechanism. J Allergy Clin Immunol. 2009;123(6):1287-96 e1282.

61. Takedachi M, Qu D, Ebisuno Y, Oohara H, Joachims ML, McGee ST, et al. CD73-generated adenosine restricts lymphocyte migration into draining lymph nodes. J Immunol. 2008;180(9):6288-96.

62. Ma SR, Deng WW, Liu JF, Mao L, Yu GT, Bu LL, et al. Blockade of adenosine A2A receptor enhances $C D 8(+) T$ cells response and decreases regulatory $T$ cells in head and neck squamous cell carcinoma. Mol Cancer. 2017;16(1):99.

63. Ohta A, Gorelik E, Prasad SJ, Ronchese F, Lukashev D, Wong MK, et al. A2A adenosine receptor protects tumors from antitumor T cells. Proc Natl Acad Sci USA. 2006;103(35):13132-7.

64. Leone RD, Lo YC, Powell JD. A2aR antagonists: next generation checkpoint blockade for cancer immunotherapy. Comput Struct Biotechnol J. 2015;13:265-72

65. Nakatsukasa H, Tsukimoto M, Harada H, Kojima S. Adenosine A2B receptor antagonist suppresses differentiation to regulatory $T$ cells without suppressing activation of T cells. Biochem Biophys Res Commun. 2011:409(1):114-9.
66. Antonioli L, Pacher P, Vizi ES, Hasko G. CD39 and CD73 in immunity and inflammation. Trends Mol Med. 2013;19(6):355-67.

67. Sauer AV, Brigida I, Carriglio N, Hernandez RJ, Scaramuzza S, Clavenna $\mathrm{D}$, et al. Alterations in the adenosine metabolism and CD39/CD73 adenosinergic machinery cause loss of Treg cell function and autoimmunity in ADA-deficient SCID. Blood. 2012;119(6):1428-39.

68. Ohta A, Madasu M, Subramanian M, Kini R, Jones G, Chouker A, et al. Hypoxia-induced and A2A adenosine receptor-independent T-cell suppression is short lived and easily reversible. Int Immunol. 2014;26(2):83-91.

69. Chen M, Liang D, Zuo A, Shao H, Kaplan HJ, Sun D. An A2B adenosine receptor agonist promotes Th17 autoimmune responses in experimental autoimmune uveitis (EAU) via Dendritic Cell Activation. PLoS ONE. 2015;10(7):e0132348.

70. Liang D, Zuo A, Shao H, Chen M, Kaplan HJ, Sun D. A2B adenosine receptor activation switches differentiation of bone marrow cells to a CD11C(+)Gr-1(+) dendritic cell subset that promotes the Th17 response. Immun Inflamm Dis. 2015;3(4):360-73.

71. Flores-Santibanez F, Fernandez D, Meza D, Tejon G, Vargas L, Varela-Nallar $L$, et al. CD73-mediated adenosine production promotes stem cell-like properties in mouse Tc17 cells. Immunology. 2015;146(4):582-94.

72. Lad D, Hoeppli R, Huang Q, Garcia R, Xu L, Toze C, et al. Regulatory T-cells drive immune dysfunction in CLL. Leuk Lymphoma. 2018;59(2):486-9.

73. Saze Z, Schuler PJ, Hong CS, Cheng D, Jackson EK, Whiteside TL. Adenosine production by human B cells and B cell-mediated suppression of activated T cells. Blood. 2013;122(1):9-18.

74. Yoshizaki A, Miyagaki T, DiLillo DJ, Matsushita T, Horikawa M, Kountikov El, et al. Regulatory B cells control T-cell autoimmunity through IL-21-dependent cognate interactions. Nature. 2012;491(7423):264-8.

75. Saulep-Easton D, Vincent FB, Quah PS, Wei A, Ting SB, Croce CM, et al. The BAFF receptor TACI controls IL-10 production by regulatory $B$ cells and CLL B cells. Leukemia. 2016;30(1):163-72.

76. Vijayamahantesh, Amit A, Kumar S, Dikhit MR, Jha PK, Singh AK, et al. Up regulation of $A 2 B$ adenosine receptor on monocytes are crucially required for immune pathogenicity in Indian patients exposed to Leishmania donovani. Cytokine. 2016:79:38-44.

77. Bergamin LS, Braganhol E, Figueiro F, Casali EA, Zanin RF, Sevigny J, et al. Involvement of purinergic system in the release of cytokines by macrophages exposed to glioma-conditioned medium. J Cell Biochem. 2015;116(5):721-9.

78. Sciaraffia E, Riccomi A, Lindstedt R, Gesa V, Cirelli E, Patrizio M, et al. Human monocytes respond to extracellular CAMP through A2A and A2B adenosine receptors. J Leukoc Biol. 2014;96(1):113-22.

79. Figueiredo AB, Serafim TD, Marques-da-Silva EA, Meyer-Fernandes JR, Afonso LC. Leishmania amazonensis impairs DC function by inhibiting CD40 expression via A2B adenosine receptor activation. Eur J Immunol. 2012;42(5):1203-15.

80. Cekic C, Sag D, Li Y, Theodorescu D, Strieter RM, Linden J. Adenosine $\mathrm{A} 2 \mathrm{~B}$ receptor blockade slows growth of bladder and breast tumors. J Immunol. 2012;188(1):198-205.

81. Challier J, Bruniquel D, Sewell AK, Laugel B. Adenosine and CAMP signalling skew human dendritic cell differentiation towards a tolerogenic phenotype with defective CD8(+) T-cell priming capacity. Immunology. 2013;138(4):402-10.

82. Novitskiy SV, Ryzhov S, Zaynagetdinov R, Goldstein AE, Huang Y, Tikhomirov OY, et al. Adenosine receptors in regulation of dendritic cell differentiation and function. Blood. 2008;112(5):1822-31.

83. Bense RD, Sotiriou C, Piccart-Gebhart MJ, Haanen JB, van Vugt MA, de Vries EG, et al. Relevance of tumor-infiltrating immune cell composition and functionality for disease outcome in breast cancer. J Natl Cancer Instit. 2017. https://doi.org/10.1093/jnci/djw192.

84. Yip KH, Lau HY, Wise H. Reciprocal modulation of anti-lgE induced histamine release from human mast cells by $\mathrm{A}(1)$ and $\mathrm{A}(2 \mathrm{~B})$ adenosine receptors. Br J Pharmacol. 2011;164(2b):807-19.

85. Leung CT, Li A, Banerjee J, Gao ZG, Kambayashi T, Jacobson KA, et al. The role of activated adenosine receptors in degranulation of human LAD2 mast cells. Purinergic Signal. 2014;10(3):465-75. 
86. Hua X, Chason KD, Jania C, Acosta T, Ledent C, Tilley SL. Gs-coupled adenosine receptors differentially limit antigen-induced mast cell activation. J Pharmacol Exp Ther. 2013;344(2):426-35.

87. Hasko G, Csoka B, Nemeth ZH, Vizi ES, Pacher P. A(2B) adenosine receptors in immunity and inflammation. Trends Immunol. 2009;30(6):263-70.

88. Gorzalczany Y, Akiva E, Klein O, Merimsky O, Sagi-Eisenberg R. Mast cells are directly activated by contact with cancer cells by a mechanism involving autocrine formation of adenosine and autocrine/paracrine signaling of the adenosine A3 receptor. Cancer Lett. 2017;397:23-32.

89. Kumar V. Adenosine as an endogenous immunoregulator in cancer pathogenesis: where to go? Purinergic Signal. 2013;9(2):145-65.

90. Young A, Ngiow SF, Gao Y, Patch AM, Barkauskas DS, Messaoudene M, et al. A2AR adenosine signaling suppresses natural killer cell maturation in the tumor microenvironment. Cancer Res. 2018;78(4):1003-16.

91. Montalban Del Barrio I, Penski C, Schlahsa L, Stein RG, Diessner J, Wockel $A$, et al. Adenosine-generating ovarian cancer cells attract myeloid cells which differentiate into adenosine-generating tumor associated macrophages - a self-amplifying, CD39- and CD73-dependent mechanism for tumor immune escape. J Immunother Cancer. 2016:4:49.

92. Csoka B, Selmeczy Z, Koscso B, Nemeth ZH, Pacher P, Murray PJ, et al. Adenosine promotes alternative macrophage activation via $A 2 A$ and A2B receptors. FASEB J. 2012;26(1):376-86.

93. Ryzhov S, Zaynagetdinov R, Goldstein AE, Novitskiy SV, Blackburn MR, Biaggioni I, et al. Effect of A2B adenosine receptor gene ablation on adenosine-dependent regulation of proinflammatory cytokines. J Pharmacol Exp Ther. 2008;324(2):694-700.

94. Cohen HB, Briggs KT, Marino JP, Ravid K, Robson SC, Mosser DM. TLR stimulation initiates a CD39-based autoregulatory mechanism that limits macrophage inflammatory responses. Blood. 2013;122(11):1935-45.

95. Koscso B, Csoka B, Kokai E, Nemeth ZH, Pacher P, Virag L, et al. Adenosine augments IL-10-induced STAT3 signaling in M2C macrophages. J Leukoc Biol. 2013;94(6):1309-15.

96. Park JH, Williams DR, Lee JH, Lee SD, Lee JH, Ko H, et al. Potent suppressive effects of 1-piperidinylimidazole based novel $\mathrm{P} 2 \mathrm{X} 7$ receptor antagonists on cancer cell migration and invasion. J Med Chem. 2016;59(16):7410-30.

97. Gomez-Villafuertes R, Garcia-Huerta P, Diaz-Hernandez Jl, Miras-Portugal MT. PI3K/Akt signaling pathway triggers $\mathrm{P} 2 \mathrm{X} 7$ receptor expression as a pro-survival factor of neuroblastoma cells under limiting growth conditions. Scientific reports. 2015;5:18417.

98. Slater M, Scolyer RA, Gidley-Baird A, Thompson JF, Barden JA. Increased expression of apoptotic markers in melanoma. Melanoma Res. 2003;13(2):137-45.

99. Slater M, Danieletto S, Gidley-Baird A, Teh LC, Barden JA. Early prostate cancer detected using expression of non-functional cytolytic P2X7 receptors. Histopathology. 2004;44(3):206-15.

100. Takai E, Tsukimoto M, Harada H, Kojima S. Autocrine signaling via release of ATP and activation of $\mathrm{P} 2 \mathrm{X} 7$ receptor influences motile activity of human lung cancer cells. Purinergic Signal. 2014;10(3):487-97.

101. Slater M, Danieletto S, Pooley M, Cheng Teh L, Gidley-Baird A, Barden JA Differentiation between cancerous and normal hyperplastic lobules in breast lesions. Breast Cancer Res Treat. 2004:83(1):1-10.

102. Bian S, Sun X, Bai A, Zhang C, Li L, Enjyoji K, et al. P2X7 integrates PI3K AKT and AMPK-PRAS40-mTOR signaling pathways to mediate tumor cell death. PLoS ONE. 2013;8(4):e60184.

103. Schneider G, Glaser T, Lameu C, Abdelbaset-Ismail A, Sellers ZP, Moniuszko M, et al. Extracellular nucleotides as novel, underappreciated pro-metastatic factors that stimulate purinergic signaling in human lung cancer cells. Mol Cancer. 2015;14:201.

104. Amoroso F, Capece M, Rotondo A, Cangelosi D, Ferracin M, Franceschini $A$, et al. The P2X7 receptor is a key modulator of the PI3K/GSK3beta/ VEGF signaling network: evidence in experimental neuroblastoma. Oncogene. 2015:34(41):5240-51.

105. Ghiringhelli F, Apetoh L, Tesniere A, Aymeric L, Ma Y, Ortiz C, et al. Activation of the NLRP3 inflammasome in dendritic cells induces
IL-1 beta-dependent adaptive immunity against tumors. Nat Med 2009;15(10):1170-8.

106. Fang J, Chen X, Wang S, Xie T, Du X, Liu H, et al. The expression of P2X(7) receptors in EPCs and their potential role in the targeting of EPCs to brain gliomas. Cancer Biol Ther. 2015;16(4):498-510.

107. Adinolfi E, Raffaghello L, Giuliani AL, Cavazzini L, Capece M, Chiozzi $P$, et al. Expression of $\mathrm{P} 2 \mathrm{X} 7$ receptor increases in vivo tumor growth. Cancer Res. 2012;72(12):2957-69.

108. Gilbert SM, Oliphant CJ, Hassan S, Peille AL, Bronsert P, Falzoni S, et al. ATP in the tumour microenvironment drives expression of $n f P 2 X 7$, a key mediator of cancer cell survival. Oncogene. 2018;38(2):194-208.

109. von Kugelgen I, Hoffmann K. Pharmacology and structure of P2Y receptors. Neuropharmacology. 2016;104:50-61.

110. Ballerini P, Dovizio M, Bruno A, Tacconelli S, Patrignani P. P2Y12 receptors in tumorigenesis and metastasis. Front Pharmacol. 2018;9:66.

111. Beavis PA, Divisekera U, Paget C, Chow MT, John LB, Devaud C, et al. Blockade of A2A receptors potently suppresses the metastasis of CD73+tumors. Proc Natl Acad Sci USA. 2013:110(36):14711-6.

112. Willingham SB, Ho PY, Hotson A, Hill C, Piccione EC, Hsieh J, et al. A2AR antagonism with CPI-444 induces antitumor responses and augments efficacy to anti-PD-(L)1 and anti-CTLA-4 in preclinical models. Cancer Immunol Res. 2018;6(10):1136-49.

113. Beavis PA, Henderson MA, Giuffrida L, Mills JK, Sek K, Cross RS, et al. Targeting the adenosine $2 A$ receptor enhances chimeric antigen receptor T cell efficacy. J Clin Investig. 2017;127(3):929-41.

114. Leone RD, Emens LA. Targeting adenosine for cancer immunotherapy. J Immunother Cancer. 2018;6(1):57.

115. Mittal D, Sinha D, Barkauskas D, Young A, Kalimutho M, Stannard K, et al. Adenosine $2 \mathrm{~B}$ receptor expression on cancer cells promotes metastasis. Cancer Res. 2016;76(15):4372-82.

116. Allard B, Longhi MS, Robson SC, Stagg J. The ectonucleotidases CD39 and CD73: novel checkpoint inhibitor targets. Immunol Rev. 2017;276(1):121-44

117. d'Almeida SM, Kauffenstein G, Roy C, Basset L, Papargyris L, Henrion $D$, et al. The ecto-ATPDase CD39 is involved in the acquisition of the immunoregulatory phenotype by M-CSF-macrophages and ovarian cancer tumor-associated macrophages: regulatory role of IL-27. Oncoimmunology. 2016:5(7):e1178025.

118. Hayes GM, Cairns B, Levashova Z, Chinn L, Perez M, Theunissen JW, et al. CD39 is a promising therapeutic antibody target for the treatment of soft tissue sarcoma. Am J Transl Res. 2015;7(6):1181-8.

119. Koszalka P, Golunska M, Urban A, Stasilojc G, Stanislawowski M, Majewski $M$, et al. Specific activation of $A 3, A 2 A$ and $A 1$ adenosine receptors in CD73-knockout mice affects B16F10 melanoma growth, neovascularization, angiogenesis and macrophage infiltration. PLOS ONE. 2016;11(3):e0151420

120. Bowser JL, Blackburn MR, Shipley GL, Molina JG, Dunner K Jr, Broaddus RR. Loss of CD73-mediated actin polymerization promotes endometrial tumor progression. J Clin Investig. 2016;126(1):220-38.

121. Yang $X$, Pei $S$, Wang $H$, Jin $Y$, Yu F, Zhou B, et al. Tiamulin inhibits breast cancer growth and pulmonary metastasis by decreasing the activity of CD73. BMC Cancer. 2017;17(1):255

122. Ren ZH, Lin CZ, Cao W, Yang R, Lu W, Liu ZQ, et al. CD73 is associated with poor prognosis in HNSCC. Oncotarget. 2016;7(38):61690-702.

123. Perrot I, Michaud HA, Giraudon-Paoli M, Augier S, Docquier A, Gros $L$, et al. Blocking antibodies targeting the CD39/CD73 immunosuppressive pathway unleash immune responses in combination cancer therapies. Cell Rep. 2019;27(8):2411-25 e2419.

\section{Publisher's Note}

Springer Nature remains neutral with regard to jurisdictional claims in published maps and institutional affiliations. 